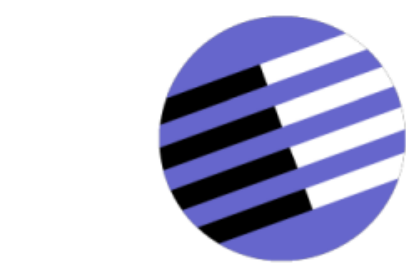

GOVERNANCE AND THE EFFICIENCY OF ECONOMIC SYSTEMS

G E S Y

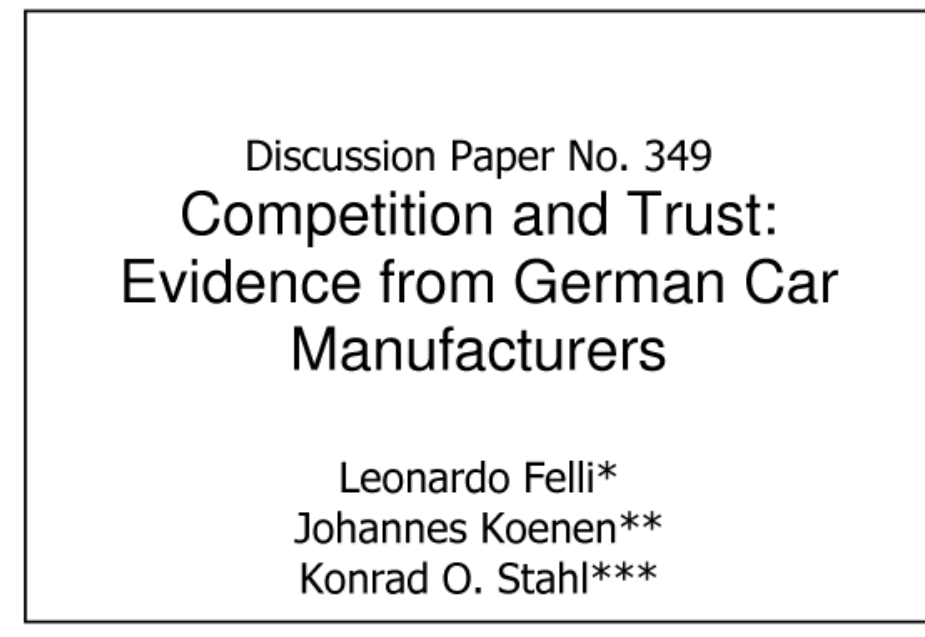

*London School of Economics, CEPR

${ }^{* *}$ University of Bonn

${ }^{* * *}$ University of Mannheim, CEPR

\title{
February 2011
}

Financial support from the Deutsche Forschungsgemeinschaft through SFB/TR 15 is gratefully acknowledged. 


\title{
Competition and Trust: Evidence from German Car Manufacturers*
}

\author{
LEONARDO FELLI \\ (London School of Economics, CEPR) \\ Johannes KoEnen \\ (University of Bonn) \\ KonRad O. STAHL \\ (University of Mannheim, CEPR)
}

February 2011

\begin{abstract}
We explore the determinants and effects of trust relationships between upstream suppliers and downstream producers. Using unique survey data on individual supplier-buyer relationships in the German automotive industry, we show, by means of different measures of supplier-buyer trust, that higher levels of trust mitigate relationship-specific underinvestment in a classical hold-up situation. Moreover, contrary to the extant literature, we show that higher levels of supplier's trust are reflected in the buyer's choice of a more competitive procurement strategy among potential suppliers.
\end{abstract}

JEL classification: D86, D22, L22, L62.

Keywords: Trust, Hold-up problem, Competition, Specific investment, Suppliers, Car manufacturers, German automotive industry.

\footnotetext{
${ }^{*}$ We acknowledge the generous hospitality of Studienzentrum Gerzensee where substantive parts of the research work were completed. We greatly benefitted from comments by seminar participants in Berlin, Copenhagen and Tel Aviv, and in particular from discussions with Chaim Fershtman, Wilhelm Rall, Klaus Schmidt and Luigi Zingales. Financial support by the Deutsche Forschungsgemeinschaft (SFB-TR-15) is gratefully acknowledged.
} 


\section{Introduction}

Trust is a key ingredient of social life. We teach children to trust each other and we all understand that in a world where social relations are governed by trust, life is simpler and more pleasant. However, when we study social interactions as economists, we tend to focus almost exclusively on selfish motives. In recent years, however, sociologists and economists has started paying attention to social interactions based on trust and fairness and the cooperative behavior induced by them. ${ }^{1}$ The implications of these concepts of trust substantively go beyond cooperation enforced by punishment threats in infinitely repeated interactions and are at the core of the theory of relational contracts. ${ }^{2}$

In these models, trust induces informal contracts that may efficiently replace legally enforced ones. In particular, if an agent trusts that he is being treated fairly by his trading partner, an efficient amount of relationship specific investment will be fostered. This is one of the general conclusions drawn from the literature on relational contracting, which we want to bring to a test. To be able to do this we need the object of trust, as recorded in the evidence, to be an individual, or a specific institution.

By contrast, most of the survey evidence on trust used to analyze its social implications, focuses on groups or large populations as the objects of trust. In particular, in the World View Survey, on which most of the empirical literature on the subject is based, respondents are asked to evaluate their trust in the population of a country. Their responses are used to analyze aggregate consequences on financial and goods markets.

To the best of our knowledge, there is very little if any empirical evidence on trust towards individuals or institutions, and its impacts on these individuals' or firms' behavior. The present paper tries to fill this gap by evaluating how trust impacts the design, production and exchange of complex products, namely the blueprints resulting from innovative investments by first tier upstream suppliers into the production of automobiles.

Upstream buyer-supplier relationships in automobile production are an extraordinarily good field in which to conduct such a study, for several reasons. The supply of a product is preceded by substantive research and development, that is at the same time buyer un-specific and buyer specific. ${ }^{3}$ The resulting intermediate product, or part,

\footnotetext{
${ }^{1}$ In Section 2 below we briefly discuss the existing literature.

${ }^{2}$ See Gibbons (2011) for a detailed account of relational contracts from an economist's perspective.

${ }^{3}$ In contrast to the US and Japan, in the Central European car manufacturing industry, upstream
} 
however, almost always exhibits buyer-specific features, and is characterized by a particularly high level of complexity. The final product, the automobile, exhibits strict complementarities between all contributing parts. In all, efficiency considerations necessitate the early and lasting co-operation between the agents involved in the design and the production of all the parts of an automobile. This however is usually associated with a superior market power on the part of the car manufacturers vis-à-vis their suppliers. In other words, there is a clear tradeoff between attaining the desired quality levels and the manufacturers' short-term incentives to extract suppliers' rents.

The data set we are basing our analysis on is a vast survey of the German car manufacturing industry conducted under the auspices of the German Automotive Industry Association (VDA). ${ }^{4}$ Within this data set we explore the object of the contract (relational or explicit) between the car manufacturers and the suppliers, the contracting environment, and both contracting partners' evaluations of their relationship. In particular, we do have survey evidence of the suppliers' perception of the contracting relationship with the automotive producers they develop and produce for, as well as the corresponding evidence of the car manufacturers' perception of the same relationship. When doing this we are able to distinguish among individual products taken from one of four categories differentiated by complexity. The contracting relationship is then documented in all development and production phases. In particular, the suppliers involved in the survey were asked about their contracting relationship by product development and production phase, product, and car manufacturer.

In order to organize our empirical analysis, we first develop a theoretical model of the procurement relationship. We extract two predictions from it. First, not surprisingly, higher levels of trust lead to higher relationship specific investments. Second, more surprisingly, an increase in trust is associated with more competition in the procurement process. The reason is that competition can be a substitute for other forms of rent extraction on the part of the car manufacturer. Stronger competition induced by the manufacturer is then associated with higher levels of suppliers' trust.

More specifically, we define an upstream supplier's trust in the downstream buyer as his belief that the buyer would not exploit his bargaining power in the hold-up situation, by extracting rents. This definition strikes us as closer to the sociological and colloquial

suppliers are responsible for much of the ground-breaking basic research, which is then adapted to the specific needs of individual car models.

${ }^{4}$ Verband Deutscher Automobilunternehmen e.V. 
reading of the term "trust". In particular, $A$ trusts $B$ to do something (or refrain from doing something) which is in $B$ 's realm of influence, if no explicit legal constraints require $B$ to behave in this way. The measures of trust that we generate are relationshipspecific instead of subject specific. We analyze the determinants of suppliers' trust in the manufacturer using their reported past behavior.

We provide hard evidence in support of the prediction that higher levels of suppliers' trust lead to higher relationship-specific investment, proxied here by the quality, namely lower failure-rates, of the specific product supplied. While this is congruent with predictions from many theoretical models, it is, to the best of our knowledge, the first empirical test of this prediction.

More surprisingly, we show that, as opposed to the extant literature on relational contracting, trust and competition between upstream suppliers and the downstream firm are not necessarily mutually exclusive. The prediction of our model is confirmed by our empirical test: More intense suppliers' competition, as induced by the buyer's procurement scheme, is associated with higher suppliers' trust in the downstream firm.

The remainder of the paper is organized as follows. After briefly outlining the related theoretical and empirical literature in Section 2, we develop, in Section 3, a simple model. We are thus able to derive two hypotheses on the effects of trust on vertical relationships. In Section 4, we first introduce the survey on which our empirical analysis is based. We then present potential measures of trust and evaluate what they capture. Section 5 develops our empirical analysis. It analyses how trust between manufacturers and suppliers is related to the two central questions, namely suppliers' (under-)investment and sourcing decisions. Section 6 concludes.

\section{Literature Review}

\subsection{Theoretical Literature}

A business relationship that does not resort to legal means of enforcement would in colloquial terms be interpreted as based on "trust". In this sense, trust is the basis for relational contracts. There is a rich theory on relational contracting in different contexts, beginning with Bull (1987) who provides the original repeated games-framework to analyze employment relationships. As far as employment contracts are concerned, 
Baker, Gibbons, and Murphy (1994) demonstrate how the combination of formal and relational contracts can lead to better results than either instrument could achieve alone. Interestingly, formal and relational contracts can be substitutes (if either works almost perfectly) or complements. ${ }^{5}$

More recently, research has focused on more general settings, searching for optimal contract design. Levin (2003) finds that while under moral hazard optimal relational contracts exist and are relatively simple, under hidden information cases arise in which agents do not respond at all to the incentives provided therein. Calzolari and Spagnolo (2009) further extend this case. While in their model the relationship between a principal repeatedly interacting with an agent can suffer from both moral hazard and hidden information, they allow the principal to screen, and select from competing, but potentially colluding agents. In situations in which non-contractible factors contribute more to the principal's payoff, they find the intuitively appealing result that the principal will rely more heavily on relational contracts with a smaller set of agents. By contrast, in "simpler" settings in which the most important issues are contractible, the principal will rely more on competition among agents.

Brown, Falk, and Fehr (2004) carry out an experimental study focussing on the effects of the enforceability of contracts. Much in line with the theoretical results described above, they find that as enforcement becomes more effective, the original long-term rent-sharing relationships are replaced by short-term arms-length agreements. In their specific setting, this can be taken as evidence that formal and relational contracts are substitutes.

The models described above have in common that relational contracts and competition are polar concepts - you either rely on handshakes or you prefer arms-length market interactions. By contrast, we show in our analytical model, as well as the empirical analysis, that trust and competition can actually be complements in a hold-up setting, if competition is used as a mechanism of extracting rent from one of several individuals, instead of resorting to extracting rents from the same individual through superior bargaining power. As the concept of trust that we propose is not fully congruent with relational contracts, our result can be seen as complementing this literature.

\footnotetext{
${ }^{5}$ See Gibbons (2011) and MacLeod (2007) surveys on the topic. In the latter survey the effects of legal systems of different quality are specifically addressed.
} 


\subsection{Empirical Literature}

Trust has for some time drawn considerable attention and scrutiny from experimental and empirical economists. ${ }^{6}$ Yet some of the more experimental literature has been rather cautious about using this term, even actively trying to avoid it (see for example the discussion in MacLeod (2007)). ${ }^{7}$ By contrast, empirical researchers have been less shy in this regard, so that some empirical analyses of trust do exist.

The basis for many empirical studies on trust is the World Values survey, and in it, the set of answers to the question: "Generally speaking, would you say that most people can be trusted, or that you have to be very careful in dealing with people?" While one may doubt the power of this construct at first glance, ${ }^{8}$ it has been used frequently in a number of studies. The basic hypothesis of La Porta, Lopez-de-Silanes, Shleifer, and Vishny (1997) is that trust is an integral requirement for the functioning of large organizations in which the likelihood of repeated interactions is relatively small, and thus the established mechanisms for ensuring cooperative behavior are less effective. In a cross-country study they establish that populations with higher levels of trust should foster more effective governance as well as relatively larger firms. Aghion, Algan, Cahuc, and Shleifer (2008) perform an international comparison on the nexus between levels of social capital (or trust/distrust), and the demand for (or the amount available) of state regulation. The intuition is that a lack of civic mindedness in one's fellow citizens may lead to a stronger desire for the state to regulate interactions. They find very strong evidence for this, even for societies in which the government itself is plagued by corruption. It therefore appears that trust and regulation are to some extent substitutes.

Guiso, Sapienza, and Zingales (2009) focus on the trust citizens of a given country in Europe have toward citizens of another country. Here the levels of trust are explained in part by the geographic distance between countries, but also by sociological and genetic closeness and common history. Less trust in the citizens of a country is associated with significantly lower aggregate trade and investment. In an another study, Guiso, Sapienza, and Zingales (2004) suggest that the different characteristics of Italian regions lead their citizens to develop different levels of social capital. They then show that

\footnotetext{
${ }^{6}$ See Fehr (2009) for an overview of the experimental and neuro-economic literature on trust.

${ }^{7}$ For a careful survey of the development of the term "culture" in economics, and the effects of culture on economic outcomes, see Guiso, Sapienza, and Zingales (2006).

${ }^{8}$ See Sapienza, Toldra, and Zingales (2007) for an experimental study on the merits of this measure and a discussion of the previous literature.
} 
in high social capital/trust areas people are more prone to invest in stocks instead of holding cash reserves, and have easier access to bank credit. The effect is mitigated by levels of education. Along similar lines, Guiso, Sapienza, and Zingales (2005) find that individuals who display higher levels of trust buy more risky assets relative to their wealth. They counter the natural question that this might be due to differences in risk attitudes by controlling for risk- and ambiguity-aversion. Their original result persists.

In contrast to the research mentioned so far, Butler, Giuliano, and Guiso (2009) study the effects of individuals' trust as opposed to trust towards groups. They use the European Social Survey as well as experimental evidence to argue that a medium amount of trust may be optimal for individuals. Too little trust may lead individuals to miss too many opportunities for beneficial interactions, while too much trust leads to the danger of being taken advantage of.

Finally, Bottazzi, Da Rin, and Hellmann (2009) study the willingness of venture capitalists to perform non-contractible services in a micro-economic environment. In particular, they analyze the influence of more effective legal systems in this context. Both in their theoretical model and their empirical analysis of a data-set on European venture-capital deals they find that a more efficient legal system has the following two effects. On the one hand, it is complementary to trust, in the sense that it makes venture capitalists more willing to grant non-contractible support. On the other hand, it leads venture capitalists to require more protection for the case of failure of the venture. ${ }^{9}$

Our empirical analysis adds a new angle to the way economists think about trust. We define trust not as a characteristic specific to individuals. Instead, we interpret trust as the expectation of one party towards future behavior of the other, based on relationshipspecific observable and unobservable characteristics, including the joint history. Based on this approach, we analyze how higher or lower levels of a supplier's trust in a buyer affect upstream investment levels, as well as the choice of contractual setting in the German automobile industry.

\footnotetext{
${ }^{9}$ In the working paper on the same data, Bottazzi, Da Rin, and Hellmann (2007) also show that higher scores on the Euro-Barometer measure of trust between nations are associated with higher crosscountry investments.
} 


\section{Analytical Framework}

We introduce in this section a simple model, with two main goals in mind: Clearly define the concept of trust that we wish to work with, and derive robust predictions that we can bring to the data and test.

In line with our observations on upstream procurement, we focus on how competition between suppliers - as induced by the original equipment manufacturer (OEM hereafter) - relates to issues of under-investment due to hold-up problems. What we observe in reality when a new part is to be developed and procured is that in many cases several suppliers are invited to develop a blueprint that is supposed to match the OEM's specifications. Depending on the development stage, these can range from extremely vague (pre-development up to 3 years in advance of series production) to rather specific (detailed development about 6-9 months prior to series production). A large part of the compensation to the supplier for the development effort is comprised in the OEM's subsequent business regarding series production or more detailed developmentbut in these later phases only a subset (often only one firm) of the previously employed suppliers will be awarded the second contract.

\subsection{Structure and Timing of the Procurement Game}

Consider a monopolistic OEM who needs the input of one supplier towards producing output of value $v\left(\theta_{i}, I_{i}\right)$, where $\theta_{i}$ designates the intrinsic quality and $I_{i}$ the effort choice of supplier $i$ to be defined exactly below.

At $t=0$, the OEM irreversibly chooses, from a large pool consisting of ex-ante identical potential suppliers, $n$ of them and invites them to develop and submit a blueprint for the part it wants to procure. The OEM incurs a cost $k$ of selecting an additional supplier in the development stage, so that the total costs associated with the development phase are $n k{ }^{10}$ Each supplier $i$ selected by the OEM independently draws an intrinsic quality parameter $\theta_{i}$ from the publicly known continuous distribution $Q(\theta)$ with domain $[0,1]$. There are many ways to interpret this parameter — for example it could

\footnotetext{
${ }^{10}$ The cost $k$ could be interpreted as the setup investment the OEM has to make with the supplier in order for the latter to develop a blueprint compatible with the model in the OEM production line. Alternatively, this could be repayment of costs that the OEM owes to each supplier involved in the development stage. In either case, for simplicity we take this cost to be independent of the supplier's investment.
} 
be regarded as a measure of how well the supplier's employees involved in the project are compatible with the OEM's engineers, or how well the research capacities of the two firms complement each other with regard to the period of time in question. Clearly there is a certain level of randomness involved here, even if the firms have cooperated in the past. In an established industry, like the automotive industry, this randomness should be similar across comparable suppliers. At any rate, after each supplier privately observes the value of $\theta_{i}$, he chooses an investment level $I_{i}$. This investment comes at a cost described by the function $c\left(I_{i}\right)$ common to all suppliers, with both $c^{\prime}$ and $c^{\prime \prime}$ strictly positive.

At $t=1$, the suppliers' qualities and investment choices become common knowledge. Only one of the suppliers receives a second contract. He is selected in the following way. If $n=1$, then this supplier is awarded the contract. Otherwise, the suppliers engage in Bertrand competition under perfectly symmetric information. Supplier $i$ proposes a bid $b_{i}$, and the supplier with the highest bid is awarded the contract.

Finally, at $t=2$, the supplier that submitted the winning bid; and the OEM bargain over how to share the joint surplus from production $v\left(\theta_{i}, I_{i}\right)$, which is strictly increasing and concave in both $\theta_{i}$ and $I_{i}$. In this bargaining process, we denote by $g$ the OEM's exogenously given outside option. The supplier's outside option is instead endogenously determined by his effort choice and is an exogenously given share $\sigma \in(0,1)$ of the surplus from production, $\sigma v\left(\theta_{i}, I_{i}\right)$. In other words, the surplus generated by the supplier's investment within the relationship is strictly greater than the surplus obtained from that investment outside the relationship. Moreover, the marginal return from the investment is also higher within the relationship than outside it.

The first best investment level $I^{*}$ is determined by the first order condition

$$
\frac{\partial v\left(\theta, I^{*}\right)}{\partial I}=c^{\prime}\left(I^{*}\right)
$$

where $I^{*}(\theta)$ denotes the first best level of investment for the supplier of type $\theta$. Any level of investment below $I^{*}(\theta)$ represents under-investment.

In what follows we analyze two polar configurations of the bargaining power in the negotiation at $t=2$. We first consider the case in which the OEM has full bargaining power (case $F B O$ ). We then consider the case in which the supplier has full bargaining power and makes a take-it-or-leave-it offer to the OEM (case $F B S$ ). One possible inter- 
pretation of these cases is that the supplier owns the property rights of the blueprints developed at $t=1$. In the $F B O$ case the OEM expropriates the supplier of these property rights without any fear of repercussions, while in the $F B S$ case the OEM honors these property rights.

\subsection{Results}

We here solve for the Subgame Perfect equilibrium (SPE) of our model distinguishing between the two cases described above. ${ }^{11}$

We start from the $F B O$ case where the whole bargaining power resides with the OEM.

At $t=2$, the OEM offers the winning supplier $i$ the fixed payment $T$ maximizing $v\left(\theta_{i}, I_{i}\right)-T$, subject to the supplier's participation constraint, so that $T \geq \sigma v\left(\theta_{i}, I_{i}\right)$. The SPE of the bargaining subgame is such that the OEM offers exactly $T=\sigma v\left(\theta_{i}, I_{i}\right)$, and the supplier accepts.

We now move backward to period $t=1$ and the Bertrand competition game among suppliers. We just have seen that the supplier awarded the second period contract will obtain an offer equivalent to his outside option, so that he is indifferent between winning and losing the bid. ${ }^{12}$ Nevertheless, the expected valuation $v$ increases in $n$ : As suppliers are indifferent, and there is symmetric information at this point, the OEM is able to select the highest-quality supplier out of $n$. Mathematically, this is a simple order statistic problem. The maximum order statistic with $n$ draws follows the distribution $Q_{1}^{n}(\theta)=[Q(\theta)]^{n}$. For a non-degenerate $Q,[Q(\theta)]^{n+1}$ stochastically dominates $[Q(\theta)]^{n}$. The corresponding expectation is therefore increasing in the number of suppliers $n$, leading to a higher expected quality $\theta_{i}$ of the highest quality supplier among the competitors, without affecting their investment incentives.

We can now move backward to $t=0$ and the supplier's investment choice. This

\footnotetext{
${ }^{11}$ When solving backward the model we restrict attention to the set of cautious equilibria of the Bertrand competition game. The basic idea behind this equilibrium concept is that no supplier should be willing to make a bid that would leave the supplier in the case he wins worse off relative to the equilibrium if he refused to participate in the Bertrand game. The dynamic version of the same equilibrium notion has been used in the analysis of Bergemann and Välimäki (1996) and Felli and Harris (1996). In our static environment a cautious equilibrium is equivalent to an equilibrium in weakly dominant strategies.

${ }^{12}$ The winning bidder receives his outside option as the outcome of $t=2$ bargaining, the losing suppliers receive it because they have to fall back on it.
} 
supplier faces the following maximization problem:

$$
\max _{I} \sigma v\left(\theta_{i}, I\right)-c(I)
$$

with first order condition

$$
\left.\sigma \frac{\partial v\left(\theta_{i}, I_{i}^{F B O}\right)}{\partial I}=c^{\prime}\left(I_{i}^{F B O}\right)\right)
$$

where $I_{i}^{F B O}$ denotes the supplier's optimal investment level as a function of $\theta_{i}$. In this setting therefore the typical supplier under-invests, so $I_{i}^{F B O}:=I^{F B O}\left(\theta_{i}\right)<I^{*}\left(\theta_{i}\right)$. The ex ante expected profit of the OEM is

$$
E \Pi_{O}^{F B O}=(1-\sigma) E\left[v\left(\theta_{1}, I^{F B O}\left(\theta_{1}\right)\right) \mid n\right]-n k,
$$

associated with the expected quality and investment of the highest quality supplier denoted $\theta_{1}$. The OEM benefits from larger $n$ only through the higher expected quality of the best supplier and extracts the entire value. The optimal $n^{F B O}$ is then chosen so that the marginal benefits from the expected profit gains is just below the costs for $n^{F B O}+1$.

Consider, now, the FBS case where the whole bargaining power resides with the supplier.

Focus first on the case $n=1$, in which a single supplier has been chosen at $t=0$. At $t=2$, the unique SPE of the bargaining subgame is for the supplier to offer the outside option, $g$, to the OEM. This outside option does not depend upon the effort provided by the chosen supplier. ${ }^{13}$ In period $t=0$, the supplier's maximization problem is

$$
\max _{I} v\left(\theta_{i}, I_{i}\right)-g-c\left(I_{i}\right)
$$

leading to the first order condition

$$
\frac{\partial v\left(\theta, I^{*}\right)}{\partial I}=c^{\prime}\left(I^{*}\right)
$$

Obviously, this contract induces first best effort choice $I^{*}(\theta)$ by the supplier, who in this case absorbs all rents of the project.

\footnotetext{
${ }^{13}$ The results from contacting another supplier do not directly depend on the effort the first supplier has provided.
} 
The case in which suppliers compete at $t=1$ differs substantially. Consider first the bargaining subgame at $t=2$ between the OEM and the supplier that prevailed in the Bertrand competition game, with the winning bid denoted $b_{1}$. We will see that in equilibrium this bid coincides with the OEM's endogenous outside option. The next question is then how high will the suppliers be willing to bid? Ignoring the investment costs that are sunk at this stage, the winner $i$ 's payoff is the total surplus of the project minus his bid, that is $v\left(\theta_{i}, I\left(\theta_{i}\right)\right)-b_{i}$, while the losing bidders $j$ still obtain their outside option worth $\sigma v\left(\theta_{j}, I\left(\theta_{j}\right)\right)$. The suppliers derive higher rents from winning the competition, as long as their bid is smaller than $\hat{b}_{i}:=(1-\sigma) v\left(\theta_{i}, I\left(\theta_{i}\right)\right)$.

At $t=1$, the suppliers compete à la Bertrand. As mentioned above, at this stage, the individual qualities and investment levels are common knowledge. ${ }^{14}$ The cautious equilibrium of the Bertrand game is for the most efficient supplier $i$, with $i=\operatorname{argmax}_{i \leq n} v\left(\theta_{i}, I\left(\theta_{i}\right)\right)$, to win by submitting an offer to the OEM, that coincides with the one submitted by the second most efficient supplier and that makes the latter indifferent between being selected or not. ${ }^{15}$ In other words, if we denote the most efficient supplier as supplier 1 and the second most efficient supplier as 2 , the equilibrium bids are $b_{1}=b_{2}=(1-\sigma) v\left(\theta_{2}, I\left(\theta_{2}\right)\right)$.

To understand the economic mechanisms at play here, it is helpful to consider the OEM's payoffs at given levels of investment and given the choice of suppliers $n$. Denote the most efficient supplier as supplier 1 and the second most efficient supplier as 2 . The OEM's payoff for given investments is simply $(1-\sigma) v\left(\theta_{2}, I\left(\theta_{2}\right)\right)-n k$, which is equivalent to the surplus the second most efficient supplier would receive if running the project, minus the OEM's costs of soliciting the $n$ offers. Ignoring the investment incentives for the moment, two effects are at play. As for the first effect: just as in the $F B O$ case the expected quality of the second best supplier improves when increasing $n$ - though because of Bertrand competition it follows the second instead of the highest order statistic distribution. This is a level effect. The OEM profits from the overall expected quality increase. To understand the second effect it is useful to first derive the surplus of the most efficient supplier net of his outside option (ignoring the sunk effort costs incurred in the previous period):

\footnotetext{
${ }^{14}$ This assumption is not necessary in this setting, as bidding their real valuations is a weakly dominant strategy in the second price auction where bidders have private information on $\theta_{i}$.

${ }^{15}$ We obtain the same outcome with a second price auction - here each supplier bids her valuation and the most efficient one pays the second most efficient supplier's bid.
} 


$$
(1-\sigma)\left[v\left(\theta_{1}, I\left(\theta_{1}\right)\right)-v\left(\theta_{2}, I\left(\theta_{2}\right)\right)\right]
$$

While in the $F B O$ case the OEM uses his bargaining power to absorb the entire surplus from cooperation no matter how many suppliers compete, now the most efficient supplier captures a share of this surplus, determined by the difference in surplus between his and the second best design. As $n$ becomes larger this difference shrinks, so that the OEM receives a greater share of the surplus. This is the second effect mentioned above.

Now we turn to the suppliers' investment decision at $t=0$. First consider the expected payoff of the supplier that is eventually awarded the production contract, conditional on the number of suppliers involved in the competition and the realization of his own quality $\theta_{i}$. This is

$$
E\left[\left(v\left(\theta_{1}, I\left(\theta_{1}\right)\right)-(1-\sigma) v\left(\theta_{2}, I\left(\theta_{2}\right)\right) \mid n, \theta_{1}=\theta_{i}\right]-c\left(I_{i}\right)\right)
$$

or

$$
\left.v\left(\theta_{1}, I\left(\theta_{1}\right)\right)-(1-\sigma) E\left[v\left(\theta_{2}, I\left(\theta_{2}\right)\right) \mid n, \theta_{1}=\theta_{i}\right]-c\left(I_{i}\right)\right) .
$$

Hence the payoff of the supplier receiving the production contract is the value produced minus his investment costs and the expected surplus generated by the second best supplier. Denote the latter term $\nu\left(\theta_{2}, I\left(\theta_{2}\right), n\right)$. This term is independent of the suppliers' investment $I\left(\theta_{1}\right)$ and increases in the number of suppliers involved for given levels of investment. Clearly, supplier $i$ does not receive this payoff with certainty, but instead he anticipates that he will be awarded the subsequent contract only if he is the most efficient supplier. Since at this point the intrinsic quality of the other suppliers is unknown, the supplier expects this event to take place with probability $p\left(\theta_{i}, I_{i}, n\right)=p\left\{v\left(\theta_{i}, I_{i}\right) \geq \sup _{j \neq i} v\left(\theta_{j}, I_{j}\right)\right\}$.

The supplier $i$ 's maximization problem at $t=0$ is then:

$$
\begin{aligned}
\max _{I_{i}} p\left(\theta_{i}, I_{i}, n\right)\left[v\left(\theta_{i}, I_{i}\right)\right. & \left.-\max _{j \neq i} \nu\left(\theta_{j}, I\left(\theta_{j}\right), n\right)\right] \\
& +\left[1-p\left(\theta_{i}, I_{i}, n\right)\right] \sigma v\left(\theta_{i}, I_{i}\right)-c\left(I_{i}\right)
\end{aligned}
$$


This leads to the first order condition with respect to optimal investment:

$$
\begin{aligned}
c^{\prime}\left(I_{i}\right)=\frac{\partial p\left(\theta_{i}, I_{i}, n\right)}{\partial I_{i}}[(1-\sigma) & \left.v\left(\theta_{i}, I_{i}\right)-\max _{j \neq i} \nu\left(\theta_{j}, I\left(\theta_{j}\right), n\right)\right] \\
& +\left[(1-\sigma) p\left(\theta_{i}, I_{i}, n\right)+\sigma\right] \frac{\partial\left(v\left(\theta_{i}, I_{i}\right)\right.}{\partial I_{i}}
\end{aligned}
$$

We observe a number of countervailing effects. On the one hand, investment incentives are somewhat diluted, as the supplier only profits from the added value with positive probability less than unity (unless $n=1$ ). On the other hand, by choosing higher levels of investment he can increase the probability that the contract will be awarded to him. Notice that, irrespective of the number of suppliers $n$, the investment incentives are strictly higher in the present $F B S$ case than in the $F B O$ case: while in the latter, the suppliers never get any share of the surplus they generate within the relationship in excess of their outside option, they get in the former case some of that surplus in expectation, even if incentives are diluted by competition. In other words, suppliers undertake higher effort in the $F B S$ case. Only as $n$ gets very large, the effort levels converge to the levels in the former case.

Denote the supplier $i$ 's investment choice in the $F B S$ case by $I^{F B S}\left(\theta_{i}\right)$, and the most and second most efficient suppliers as supplier 1 and supplier 2, respectively, the expected profits of the OEM in this case are

$$
E \Pi_{O}^{F B S}=(1-\sigma) E\left[v\left(\theta_{2}, I^{F B S}\left(\theta_{2}, n\right)\right) \mid n\right]-n k .
$$

At first blush, equations (3) and (9) may be interpreted as the OEM's profits are necessarily higher in the $F B O$ case, as one is comparing the first with the second order statistic. But unlike the $F B O$ case, in which the supplier's investment level was not affected by the choice of $n$, here the supplier's investment choice does depend on the level of competition and is, at the same time, strictly larger than above. As a result, we cannot in general rank the two profit levels.

This is the key tradeoff. In the short run (for given suppliers' investments) the expropriation of the supplier leads to higher profits for the OEM. However, in the long run, when the suppliers' investments adjust to the new situation this dominance is not necessarily true. In Section 3.3.1 below we reinterpret this tradeoff in terms of trust and competition. 
We consider now the OEM choice of the optimal number of suppliers in the two cases. In the $F B O$ case, the only effect of increasing $n$ is that the expected quality of the best supplier increases. In the $F B S$ case, instead, three different effects are in play. First, as in the $F B O$ case, the higher $n$, the higher the expected quality of supplier although here only the quality of the second most efficient supplier matters. Second, the higher $n$, the higher is the share of the surplus absorbed by the OEM. Third, a higher $n$ decreases each supplier's chance of being the winner of the production contract and hence decreases the typical supplier's incentive to invest. It is clear that if the first two effects are the dominant ones the overall effect of an increase in $n$ is greater in the $F B S$ as opposed to the FBO case. In other words, the OEM would choose a higher $n$ in the FBS case, were it not for the investment effect. Indeed, when $n \rightarrow \infty$, the second order statistic approaches the first order statistic from below. As both are monotonic increasing, the slope of the second order statistic must be strictly greater. As a result, the OEM will choose a higher $n$ in the $F B S$ case than in the $F B O$ one. This is true unless the investment-deterring effect of increasing $n$ is "large" relative to the other two effects.

Consider a parameterized example illustrating this result. Let supplier quality be uniformly distributed so that $Q(\theta)=\theta$, the typical supplier's investment cost function be $c(I)=I^{2} / 2$, the surplus derived from cooperation be $v(\theta, I)=\theta I$, and the OEM's outside option be $g=0$. The closed-form solutions to this example are summarized in the following table:

\begin{tabular}{|c||c|c|c|}
\hline & $I(\theta)$ & $E(v)$ & $E \Pi_{O}$ \\
\hline$F B O: n=1$ & $\sigma \theta$ & $\frac{\sigma}{3}$ & $\frac{\sigma(1-\sigma)}{3}-k$ \\
\hline$F B O: n>1$ & $\sigma \theta$ & $\frac{\sigma n}{n+2}$ & $\frac{\sigma(1-\sigma) n}{n+2}-n k$ \\
\hline$F B S: n=1$ & $\theta$ & $\frac{1}{3}$ & $-k$ \\
\hline$F B S: n>1$ & $(1-\sigma) \theta^{n}+\sigma \theta$ & $\frac{(1-\sigma) n}{2 n+1}+\frac{\sigma n}{n+2}$ & $\frac{\sigma(1-\sigma) n(n-1)}{(n+1)(n+2)}+\frac{(n-1)(1-\sigma)^{2}}{2(2 n+1)}-n k$ \\
\hline
\end{tabular}

Table 1: Parameterized Example $\left(Q(\theta)=\theta, c(I)=I^{2} / 2, v(\theta, I)=\theta I\right)$.

In the FBS case, the suppliers' investment is higher by $(1-\sigma) \theta^{n}$ than in the FBO case. When $n$ increases, investment incentives decrease, but due to the functional form, as $\theta \rightarrow 1$, this effect becomes progressively smaller. In other words, the "wedge" in the expected value of $v$ between the $F B O$ and the $F B S$ cases is strictly positive even as the number of suppliers increases unboundedly. 


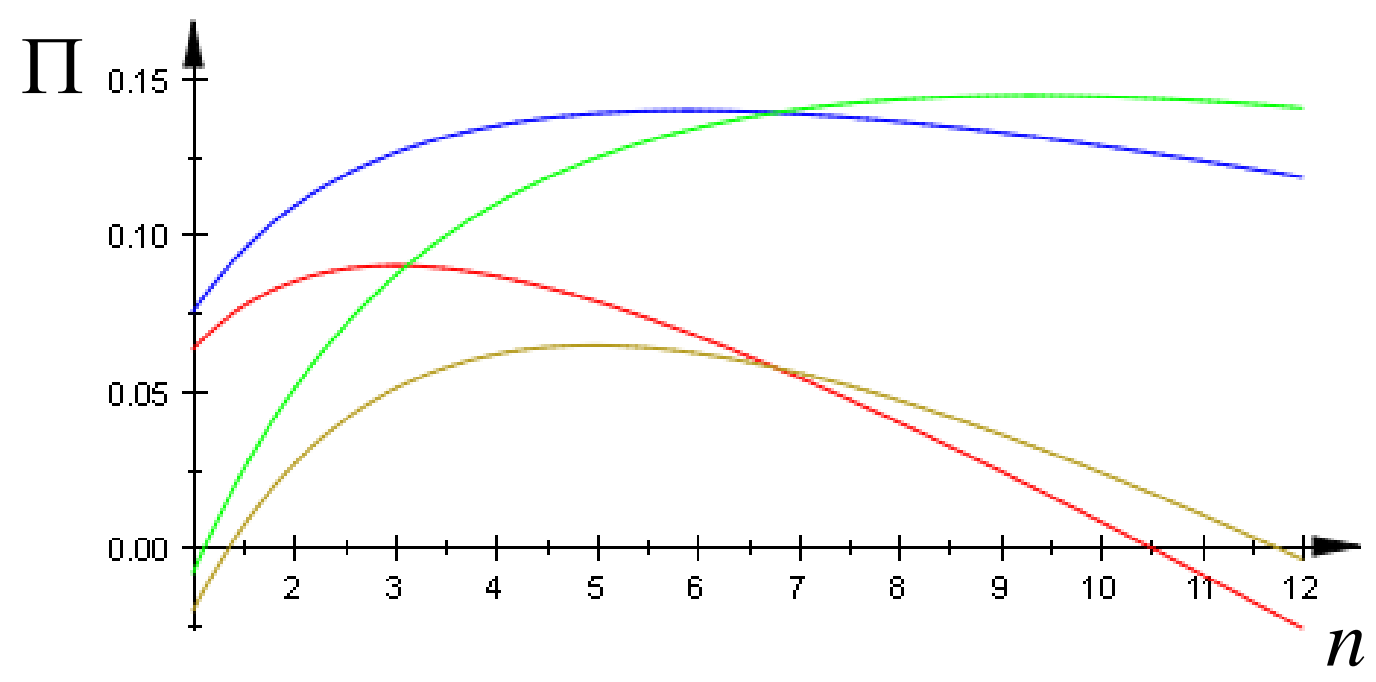

Figure 1: OEM's expected profits depending on $n$ (Blue: $\Pi_{O}^{F B O}$ (low $k$ ); red: $\Pi_{O}^{F B O}$ (high $k)$; green: $\Pi_{O}^{F B S}\left(\right.$ low $k$ ); brown: $\Pi_{O}^{F B S}($ high $k)$ ).

As for the optimal choice of $n$, we can compare the expected profits in the third column of Table 1. First, compare only the first terms of $E \Pi_{O}^{F B O}$ and $E \Pi_{O}^{F B S}$. The term in the $F B S$ case starts out at 0 and approaches the level of the first term in the $F B O$ case as $n \rightarrow \infty$. As discussed above, this isolates the effect of the second order statistic approaching the first order one for given investment levels. The second term of $E \Pi_{O}^{F B S}$ is also strictly increasing in $n$, which reflects the higher share of the (larger) total surplus being captured by the OEM. Therefore $\left(\partial E \Pi_{O}^{F B S}\right) /(\partial n)>\left(\partial E \Pi_{O}^{F B O}\right) /(\partial n)$ and the OEM's optimal choice of $n$ is larger in the $F B S$ case than in $F B O$ one. Figure 1 depicts the OEM's profits in these two cases and provides an example where the optimal choice of $n$ is larger under $F B S$ than under $F B O$ for both high and low values of $k$. Notice that while it is not clear whether expected profits are higher under $F B S$ or $F B O$, in general, the optimally chosen $n$ is such that: $n^{F B O}<n^{F B S}$.

\subsection{A Model of Trust}

\subsubsection{Definition of Trust}

We have not yet discussed how trust enters in our setting. Assume that prior to the investment choice, it is not certain which case will be relevant later on in the game. 
With probability $\lambda$ it is the supplier who makes the take-it-or-leave-it offer in period 2 ( $F B S$ case), while with probability $1-\lambda$ it is the OEM who makes the offer ( $F B O$ case). Hence with probability $\lambda$ the supplier is able to capture a share of the surplus in excess of his outside option.

How does this relate to what happens in the industry? In our interviews with industry executives a clear picture emerged: The OEMs are at great liberty in designing and enforcing contractual details in their relationship with suppliers, almost irrespective of the size or market power of their counterparts. ${ }^{16}$ At first glance therefore it would appear that only the FBO case described above (allotting the entire bargaining power to the OEM) provides an accurate description of reality. This confrontational setting, in which the relationship is defined mainly through the pure holdup-problem, is often subsumed under the term of "American procurement strategy." 17 Yet traditionally, cooperative relationships are prevalent in the Japanese automotive industry and were common practice in Germany at least up until the mid-90s. ${ }^{18}$ In other words, it is possible to interpret $\lambda$ as a measure of the mutual trust relationship between the supplier and the OEM that quantifies the share of the surplus in excess of the outside option, the OEM will leave to the supplier in spite of having full bargaining power.

An alternative interpretation of $\lambda$ could be generated by interpreting our game as the stage game of an infinitely repeated game. If we restrict ourselves to Markov strategies and think of $\lambda$ as the state variable that summarizes the previous history of play, then when the stage game we observe is played, $\lambda$ is given and represents the players' beliefs that the FBS case will apply, that is the probability with which the OEM respects the supplier's property rights. This is the definition of trust we will use in the reminder of the paper. Higher values of $\lambda$ denote a higher belief that the OEM will grant the supplier the full value of the surplus generated within the relationship (in excess of his

\footnotetext{
${ }^{16}$ See Müller, Stahl, and Wachtler (2008) for details. Ben-Shahar and White (2006) report equivalent or even more dramatic findings for the North American automobile industry.

${ }^{17}$ Yet the global success of Japanese carmakers beginning in the $80 \mathrm{~s}$ has prompted much interest in alternative ways of supply-chain management, perhaps most famously incarnated in the MIT's International Motor Vehicle Program. As a result, researchers started to stress the importance of cooperative and mutually beneficial relationships between OEMs and suppliers in the industry in achieving the goals of lean production. In this context, Taylor and Wiggins (1997) and in a more general setting Aghion, Dewatripont, and Rey (2002) show that granting the suppliers positive rents can be a substitute for control (i.e. monitoring quality levels and penalties).

${ }^{18}$ By then, an influential managagement personality, Ignacio Lopez, pushed for arms length contracting, which upset the upstream relationship for some of the German OEMs. This is one important reason for the observed variations in our data set that is key in explaining the relationships in question.
} 
outside option) - in other words, the higher $\lambda$, the more the supplier trusts that the OEM will not exploit his superior market power that we are taking for granted.

We do not spell out here the infinitely repeated game. First, the data set on which we base our empirical analysis is cross-sectional without a panel-dimension. Therefore, what we observe can be considered exactly a one stage game, in which the current levels of trust are exogenously given. Second, looking at this reduced form allows us to remain agnostic about the reasons for the OEM wanting to grant the supplier a share of the surplus. As in Taylor and Wiggins (1997) and Aghion, Dewatripont, and Rey (2002) there could be a tradeoff between rent extraction and costs of control, or it may be worth while to make the supplier fear the consequences of the relationship being terminated as in Akerlof and Yellen (1990).

We can, therefore, summarize our definition of trust as follows: In a bilateral relationship affected by a hold-up problem, we consider trust as the belief by the party with no bargaining power that its counterpart will not exploit its stronger bargaining position by appropriating the whole surplus from the relationship.

\subsubsection{Empirical Hypotheses}

We are now ready to specify the two predictions of our analysis that we want to bring to the data.

Hypothesis 1 Higher levels of supplier trust in the OEM are associated with higher relationship specific investments by suppliers.

As seen in Subsection 3.2 above, this holds for any given procurement strategy chosen by the OEM - but even this reduced form model conveys some of the complexity of the procurement decision, which also depends on the level of quality uncertainty regarding the product. Clearly, all else given, higher levels of quality uncertainty will induce procurers to induce competition between more suppliers.

While we get a straightforward prediction as to the relationship between trust and investment, the analysis regarding the level of competition induced by the OEM is more complex and surprising. In a large part of the relational contracting literature, it is argued that depending, for example, on the enforceability of complex clauses, competitive arms-length agreements on the one hand and relational contracts on the other will 
be used in mutually exclusive settings. Supported by these findings one might expect,

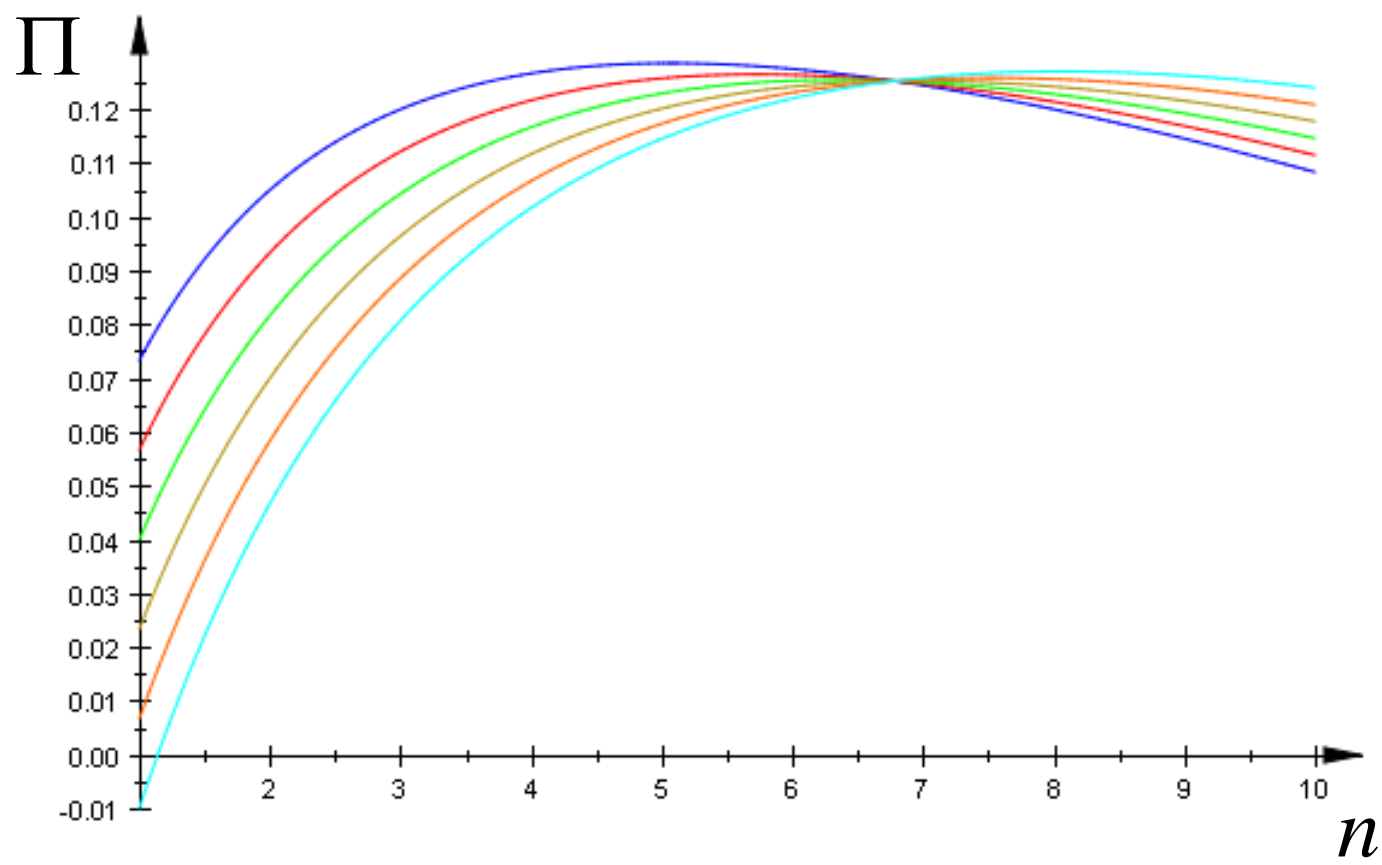

Figure 2: OEM's expected profits depending on $n$ for different values of $\lambda$ (Blue: 0.0 ; red: 0.2 ; green: 0.4 ; brown: 0.6; orange: 0.8 , cyan: 1.0 ).

at first blush, that supplier-OEM relationships governed by trust (with relatively high $\lambda$ ) should be associated with less induced competition (lower $n$ ). Yet our model above shows that generically the opposite is true, as $\lambda$ simply generates a convex combination between the two cases, in the $F B S$ case a higher level of competition is optimally induced. For the numerical example detailed in Table 1 above, Figure 2 displays how the optimal $n$ increases as $\lambda$ increases from 0 to 1 .

The intuition behind this result is as simple as it is striking. In the FBO setting, the OEM extracts the supplier's entire rent through his superior bargaining position, exploiting the existing hold-up situation. In the $F B S$ setting, he forgoes this opportunity. Yet by inducing competition by a choice of a higher $n$ he uses the endogenous outside option, that does not directly affect the supplier's investment incentives, to extract rent. The result is that trust and competition are complements. Our second hypothesis from the formal model is then:

Hypothesis 2 Higher levels of supplier trust in the OEM are associated with more 
intense supplier competition in the procurement process.

In what follows we bring both Hypotheses 1 and 2 to the data and test whether they are reflected in what we observe in the German car manufacturers industry in recent years.

\section{Data and Descriptive Statistics}

\subsection{Data Source}

Our data are the outcome of an online questionnaire study that we conducted under the auspices of the VDA between Fall 2007 and Summer 2008. The questionnaire design was based on the results of a pilot study performed in Spring 2007, in which we conducted numerous interviews with high ranking executives in the industry. ${ }^{19}$ The questionnaire data provide us with a unique view of the relationship between OEMs and their first-tier suppliers. Each participating supplier was asked to evaluate its relationship with each OEM it supplied for in Germany in clinical detail, separately for up to four products representative for each of the four product classes (detailed below) of an established industry classification. The questionnaire consisted of more than 300 questions covering all central functions within the firms. ${ }^{20}$ The four product classes are:

Commodities: physically small and technologically unsophisticated (e.g. shock absorbers);

(High-tech) Components: physically small but technologically sophisticated (e.g. electronic sensor clusters);

Modules: physically large but technologically unsophisticated (e.g. front ends);

Systems: physically large and technologically sophisticated (e.g. break systems).

In total, more than 1,500 questionnaires were filled in by competent engineers, procurement and sales officers. A participant first would have to indicate his function within

\footnotetext{
${ }^{19}$ For the qualitative results of this case study, see Müller, Stahl, and Wachtler (2008).

${ }^{20}$ In addition, the OEMs were asked to provide a general evaluation of their sourcing relationships for each of the four different product classes.
} 
the company out of the following seven: ${ }^{21}$ pre-development ("basic" technological research, not model-specific technological development), vehicle development (car-model specific technology adaptation), series production, quality control, sales, logistics, aftermarket. Finally, the participant was asked to choose a product for which he had the necessary know-how, as well as the customers he worked with. For each product and customer, he would then answer the set of questions suited to his function within the company.

In our data set, we define one observation to be the set of answers to the entire supplier questionnaire for a given product and customer. Potentially, therefore, multiple individuals, working for the same supplier, provided answers to different parts of the questionnaire. In order to obtain observations that covered as much of the questionnaire as possible, we merged the answers received from a given supplier for a given product class and customer over all functions to cover all aspects of the relationship. ${ }^{22}$ Each observation describes one supplier view of the relationship with a given OEM for one product representative for the technical class. ${ }^{23}$

\subsection{Descriptive Statistics}

With the underlying questionnaire we sought to depict complex relationships in hitherto unmatched detail. Therefore, we first introduce (perhaps in more than usual detail) the variables we focus on, in the hope to shed some light on the basic forces and tensions that are at play between manufacturers and suppliers.

\subsubsection{Participating Companies, Class Specification and Bargaining Power}

On the OEM side, 10 of the 11 manufacturers producing in Germany participated in the survey, 7 producers of passenger cars and 3 truck makers. Upstream 13 suppliers active in the German market completed the survey on 11 OEMs (the 10 participating

\footnotetext{
${ }^{21}$ For a detailed description of the individual functions and the automobile development and production process, we refer to Müller, Stahl, and Wachtler (2008). The characteristics of Pre-development, Development and Series Production is discussed in Section 4.2.2.

${ }^{22}$ Whenever parts of questionnaires overlap, we use the arithmetic mean of the answers.

${ }^{23}$ We do have missing observations for two potential reasons: First, the questionnaire was not necessarily completed for each product within each function of a company. Second, participants occasionally skipped individual questions. Therefore the number of observations over questions differs, as reported in the descriptive statistics below. In addition to this, not every supplier cooperates with every OEM in the study.
} 
car manufacturers plus one). The supplier sample is strongly biased towards large participants, with average revenues in 2007 of 9.4 billion Euro (std 12.4). Even the smallest participant posted revenues of more than 700 million Euro. This is reflected by the self-reported European market shares for the individual products in our sample: This was provided on a 5-point scale with an average of $3.76(\operatorname{std} 0.90)$, which translates into a share of more than $25 \%$ of the European market. The correlation of market share with the intensity of supplier competition - also on a 5-point scale - is negative with a value of -0.20 (significant at 5\%-level), and so is the correlation of supplier size (measured by the 2007-revenues in billion Euros) with the perceived intensity of supplier competition (-0.144, p-value 0.072). Finally, suppliers' size and market share correlate positively (0.124, p-value 0.083).

One might worry that the larger suppliers are able to exert monopoly power over OEMs for some of the parts we study. As a result we might pick up the effects of differentials in relative bargaining power instead of differentials in trust, as discussed in the theoretical model above. Using data from a separate commercial database, ${ }^{24}$ we verified that each product in our sample was produced by at least two firms active in the German market. Further, we use proxies to control for relative market power in our regressions, as this may clearly affect bargaining strength and the OEM's outside option, as described below.

The first proxy for relative bargaining power is the relative size of the companies, therefore we include the 2007 revenues of suppliers in the regressions. The second set of proxies is related to the product class or type specification introduced above, which are strongly related to relationship specificity: Suppliers were asked to estimate the R\&D-share of total costs as well as assess the importance of the degree of innovation for the particular part. Both items are measured on a 5-point scale - the importance ranging from 1, "very little", to 5, "very high" — while the R\&D cost-shares were provided in $2 \%$ increments - ranging from less than $2 \%$ to more than $8 \%$. As one would expect, the answers to the questions are strongly correlated (0.27, p-level below $0.1 \%$ ). More interestingly, though, this grants us a better understanding of the underlying typeclassification. Table 2 displays the descriptive statistics for these questions by underlying product class.

Performing pairwise t-tests shows that the means for both variables are significantly

\footnotetext{
24 "Who supplies whom" collected by supplierbusiness.com.
} 


\begin{tabular}{|l||c|c|c|c|}
\hline \multicolumn{1}{|l||}{ Variable } & Mean (Std. Dev.) & Min & Max & Obs \\
\hline Systems & $4.19(1.43)$ & 1 & 5 & 37 \\
\hline Cost Share R\&D & $4.16(.74)$ & 1 & 5 & 50 \\
\hline Importance R\&D & \multicolumn{5}{|l|}{} \\
\hline Modules & $2.06(1.76)$ & 1 & 5 & 18 \\
\hline Cost Share R\&D & $2.89(.76)$ & 1 & 4 & 18 \\
\hline Importance R\&D & $3.48(1.40)$ & 1 & 5 & 21 \\
\hline Components & $3.42(.87)$ & 2 & 5 & 45 \\
\hline Cost Share R\&D & \multicolumn{5}{|l}{} \\
\hline Importance R\&D & $2.35(1.35)$ & 1 & 5 & 91 \\
\hline Commodities & $2.91(.69)$ & 2 & 4 & 93 \\
\hline Cost Share R\&D &
\end{tabular}

Table 2: Importance of Innovation and Cost share R\&D by product type.

lower for commodities and modules than for systems and components, while among these two groups the hypothesis of equal means cannot be rejected, which is in line with the product class specification. To use as many of our observations as possible, we capture the technological sophistication of a part (and, in a sense, the specificity of the relationship) by introducing a dummy variable which takes the value 1 if the part is a system or component. We also introduce a dummy taking the value 1 for systems and modules, in order to account for potential price differences due to the sheer size of the part. To account for potential system-specific effects, we also introduce the interaction term between the two dummies. ${ }^{25}$ Finally, to capture remaining effects of market structure, we include "customer fixed effects," that is dummies for each of the individual OEMs in the regressions.

\subsubsection{Product Development Life-cycle and Supplier Competition}

In our theoretical model, we depict two different stages in the development life-cycle of a product: The development stage, in which suppliers invest to create a blueprint, and the production phase, in which the surplus is generated and allocated. While clearly a simplification, this structure is mirrored in our data. Indeed, we observe three distinct phases in the product life-cycle: pre-development, development and series production. Below, we briefly sketch these phases and describe how we use them in our empirical

\footnotetext{
${ }^{25}$ In what follows, in particular in the regression tables, these variables are labled "tech. soph.," "size of part" and "interaction," respectively.
} 
approach.

In series production, suppliers work with existing blueprints and completely designed (or existing) tools to produce the part in question. The product and services can be clearly specified through contracts, determining in detail, for example, acceptable failure rates and delivery conditions. None of this is possible in the model-specific development phase. While the desired functionality of a part can be described, potentially highly complex interfaces with other parts cannot be specified ex-ante. Blue-prints for the part do not exist at the beginning of the design phase, indeed they are the outcome of such a phase. The evolution of interfaces in the course of the part's (and other parts' simultaneous) design poses limitations to precise specifications in ex ante contracts; this requires a continuous cooperative process. Pre-development covers $\mathrm{R} \& \mathrm{D}$ on new technology, often purely based on the supplier's initiative. By necessity, even if this involves contracts, they cannot be clearly specified. For example, take the design of a new brake-technology: Engineers may have no knowledge of how fast or heavy is the car model, in which this breake-system will be implemented. Pre-development often involves fundamental research, as a result it is even harder to write enforceable contracts on the expected outcomes. ${ }^{26}$

How do the OEMs' procurement decisions differ over the different development phases? Parallel to the theoretical model, we asked how many competing suppliers worked on the product in question within each of the design and production stages. For this set of questions, the development stage was further subdivided into the four subphases (starting with the earliest): product planning, product specification, concept development and detailed development. Detailed development generates the final blueprint - this is what we interpret as the investment period in our theoretical model. For series production, we observe the number of suppliers at series start, after 1-2 years and after more than 2 years.

For pre-development on average more than two (2.16) suppliers compete. ${ }^{27}$ This number stays about constant in the first three stages of development, before it significantly decreases for the last development phase down to $1.51 .^{28}$ It reaches its nadir

\footnotetext{
${ }^{26}$ Overall, it is to be expected that contracts in the earlier phases are less specific, and rely on enforceability by repeated relationships, while contracts written in the production phase are more specific and rely on enforceability by the courts. See Brown, Falk, and Fehr (2004) for experimental evidence on a similar question.

${ }^{27}$ See Table 9 in the Appendix.

${ }^{28}$ See Table 10 in the Appendix.
} 
at the beginning of series production with 1.20, before it increases again to 1.59 two years into production. ${ }^{29}$ How can we interpret these results? During pre-development, the OEMs have multiple hand-picked suppliers work in parallel on the designs. The most promising approach is brought into the development process. As the contractual reimbursement for pre-development work is on average below $60 \%$ of the actual costs, whether or not the company is awarded a subsequent development contract, there is a strong incentive for suppliers to do everything possible for their preliminary design to be selected. An analogous process is repeated again for the development process, resulting in the specific blueprint. With this, the quality uncertainty is practically eliminated, given that firms are generally certified through stringent quality assurance processes. In production, fewer suppliers with higher volumes promise the highest economies of scales and the steepest learning curves. In addition, obtaining a sole production contract is the carrot waiving in front of the suppliers in the previous design and investment process. Therefore the number of suppliers drops significantly at production start, in most cases down to a sole producer. Once the learning curve effects have been realized, the OEM can start to bring additional suppliers in.

These considerations are supported by a second set of observations. The respondents were asked to specify how often different procurement strategies are employed by the OEM for the product class in question in each of the different stages. ${ }^{30}$ For pre-development, the options offered were preselection of a specific supplier and procurement among a limited number of suppliers, each on a 6-point scale from 1 (never) to 6 (very frequently). For development and series production, open procurement was added as a further option. From the above, we would expect a shift from relational to more arms-length contracting over the three phases and the results clearly support this hypothesis.

For pre-development, OEMs are significantly more likely to contract with specific suppliers (mean 4.43) than to go through a limited competitive procurement process (mean 3.95, t-test for difference of means significant at $1 \%$ level). ${ }^{31}$ In contrast to this, pre-selection of suppliers is significantly less likely both for development (mean 3.06)

\footnotetext{
${ }^{29}$ See Table 11 in the Appendix.

${ }^{30}$ Note that there is substantial variation in this measure as the pre-development, development and production of parts are often procured separately. In addition, production is frequently procured anew for each new series of a given model. There may be a new procurement process every 18 to 24 months, and different strategies could be used at different points in time.

${ }^{31}$ See Table 9 in the Appendix.
} 
and series production (mean 2.98). ${ }^{32}$ For development, the OEMs are significantly more likely to procure among a limited number of suppliers (mean 5.18), so there is a clear shift to more market-based interactions from pre-development to development. ${ }^{33}$ Similarly from development to series production, where procurement among a limited number of suppliers grows less important (mean 4.55), but there is a significant increase in the use of open procurement (2.44 instead of 1.97$){ }^{34}$

\subsection{Measures of Trust}

Trust is a sensitive concept which has proven to some degree elusive to attempts at explanation and measurement by economists. Existing studies have mostly employed either experimental/behavioral evidence, or subjects' answers to variations on the question "Can other people be trusted in general?" so the addressees of trust were not specified. In contrast, our data has the advantage that it is relationship-specific. We ask representatives of company $A$ about their specific evaluation of the trust relationship with company $B$ with regard to the interactions concerning a type of product in three ways, each with a slightly different emphasis:

1) What is the importance of trust for your firm's decision to initialise a pre-development with the OEM?

2) How do you evalute mutual trust between OEM and supplier with respect to honoring each others intellectual property rights?

3) Please evaluate the importance of mutual trust between the supplier and OEM for the OEM's supplier selection (respectively for each of the 3 product developments stages)

In a separate appendix, ${ }^{35}$ we show in detail that the resulting measures are strongly positively correlated with each-other, as well as by which measures of OEM behavior, such as aggressive price re-negotiations, they are affected. In addition, we perform a factor analysis to demonstrate that significant shares of the variation in the measures

\footnotetext{
${ }^{32}$ See Tables 10 and 11 in the Appendix, respectively.

${ }^{33}$ See Table 10 in the Appendix.

${ }^{34}$ See Tables 10 and 11 in the Appendix.

${ }^{35}$ Available at: Trust Appendix.
} 
can be explained by a single underlying factor. In the analysis below we use the third measure, in our view the most consistent of these measures both in terms of the phrasing of the question as well as the results of the factor analysis.

For these questions, suppliers were asked to evaluate the OEM's supplier choice criteria on a six-point scale from 1 (no relevance) to 6 (very important), for each of the phases in the product life-cycle. In the immediate context, they were also asked to evaluate the importance of price on the same scale. To counter idiosyncratic answers, we normalize the trust answers by taking differences between the importance of trust and price. To make use of as much available information as possible, we use the arithmetic mean of the normalized answers over the three product development stages as our trust measure, which has a mean of -.646, a minimum of -4 , a maximum of 2.33 and a standard deviation of 1.02 , with 229 observations. ${ }^{36}$

\section{Empirical Analysis}

In this section, we directly test the two hypotheses generated in the theoretical section using this trust measure. Each question is related to central aspects of the buyer-supplier relationships: First we study how trust is related to relationship specific investment, and then we consider the correlation between trust and the level of supplier competition induced by the OEM (measured by the number of competing suppliers).

There is one important caveat. Due to the cross-sectional structure of our data set, determining the direction of causality is an issue. One can make the argument that higher investment by suppliers leads to higher levels of trust in the OEM: Less investment may lead to more conflicts between the parties, which in turn deteriorates trust. Alternatively, one can argue the reverse causality in our second hypothesis: An improved trust relationship leads the OEM to induce more competition in procurement. The latter argument is perhaps less convincing. In any case, in the following we refer to correlation between trust and competition rather than causality.

\footnotetext{
${ }^{36}$ We also performed the regressions below with the individual measures. The results are qualitatively the same, though the significance levels vary, mainly due to smaller numbers of observations. Using a non-normalized measure also does not significantly alter results.
} 


\subsection{Trust and Investment}

Hypothesis 1 from our model states that higher levels of trust should be associated with more relationship specific investment by suppliers. Measuring supplier investment poses a serious challenge. As we do not observe product-specific investment directly, ${ }^{37}$ we apply proxies based on the quality of parts. It is a standard interpretation of quality related effort in the literature that supplier investment directly affects the failure rates of parts (see, for example, Taylor and Wiggins (1997)).

Along these lines, respondents were asked: With respect to the part considered, how often do quality problems occur?, measured on a 5-point scale, with 1 identifying the lowest and 5 the highest frequency. We create a dummy variable which takes the value 1 only if no quality problems occur, that is a 1 was reported for the quality question. In general, severe difficulties would arise when trying to assess under-investment-related quality issues empirically, as a) the observed failure rates of cars cannot necessarily be linked to individual parts, b) the diligence of the manufacturer in assembly also affects quality and c) if quality problems are diagnosed and solved before the parts are installed, this is generally not observable. The huge advantage of our questionnaire is that the responses are part-specific, which addresses issue a). The phrasing of the question addresses issue c), as it was meant to include all of the development and production phases involving the part in question. By including customer- or OEM-effects in the regressions, we address issue b). ${ }^{38}$

We choose the following Probit specification, with $y_{i j}$ denoting the probability that no quality problems arise with part $i$ at $\operatorname{OEM} j, \kappa$ a constant, $\alpha$ the customer fixed-effect, and $Z$ representing the control variables (dummies for the technological sophistication and size of the part, the interaction term, and the supplier revenues in 2007): ${ }^{39}$

$$
y_{i j}=\kappa+\alpha_{j}+\beta * \text { trust }_{i j}+\gamma * Z_{i}+\epsilon_{i j}
$$

Our hypothesis predicts a positive coefficient for $\beta$. We estimated the model with

\footnotetext{
${ }^{37}$ In our qualitative interviews, the suppliers stated that even they themselves have difficulties in specifying the development costs or the capital outlay for the production of a particular part.

${ }^{38} \mathrm{~A}$ potential drawback is the fact that the frequencies are self-reported, so that respondents may be tempted to under-report problems. To counter this, complete anonymity was guaranteed at the outset of the study.

${ }^{39}$ To address the original question, we also perform ordered-Probit regressions, the results can be found in the same Table 3. Notice that due to the phrasing in the definition of the dummy, the effects in these regressions move in opposing directions.
} 
and without customer dummies. The results of the regressions can be found in the following Table $3{ }^{40}$

\begin{tabular}{|c|c|c|c|c|}
\hline \multirow{2}{*}{$\begin{array}{l}\text { Variables } \\
\text { trust index }\end{array}$} & \multicolumn{2}{|c|}{ Probit results } & \multicolumn{2}{|c|}{ Ordered-Probit results $^{\Upsilon}$} \\
\hline & $.083^{*}$ & $.135 * *$ & -.151 & $-.271 * *$ \\
\hline & $(.054)$ & $(.012)$ & $(.126)$ & $(.026)$ \\
\hline \multirow[t]{2}{*}{ tech. soph. } & -.096 & -.135 & .267 & $.468^{*}$ \\
\hline & $(.381)$ & $(.235)$ & $(.161)$ & $(.091)$ \\
\hline \multirow[t]{2}{*}{ size of part } & $-.203^{*}$ & $-.213^{*}$ & $1.061^{* * *}$ & $1.072^{* * *}$ \\
\hline & $(.089)$ & $(.079)$ & $(.000)$ & $(.001)$ \\
\hline \multirow[t]{2}{*}{ interaction } & .012 & .052 & -.698 & $-.794^{*}$ \\
\hline & $(.937)$ & $(.752)$ & $(.108)$ & $(.076)$ \\
\hline \multirow[t]{2}{*}{ supplier revenues } & -.001 & .002 & -.007 & -.006 \\
\hline & $(.873)$ & $(.690)$ & $(.406)$ & $(.485)$ \\
\hline cut1 & & & .262 & .141 \\
\hline (std. err.) & & & $(.232)$ & $(.360)$ \\
\hline cut2 & & & 1.962 & 1.901 \\
\hline (std. err.) & & & $(.278)$ & $(.387)$ \\
\hline cut3 & & & 2.294 & 2.245 \\
\hline (std. err.) & & & $(.302)$ & $(.404)$ \\
\hline cut4 & & & 2.745 & 2.710 \\
\hline (std. err.) & & & $(.356)$ & $(.448)$ \\
\hline OEM-FE & no & yes & no & yes \\
\hline \# obs. & 138 & 138 & 138 & 138 \\
\hline $\mathrm{Ps}_{\mathrm{s}} \mathrm{R}^{2}$ & .065 & .103 & .065 & .092 \\
\hline
\end{tabular}

Table 3: Trust and Investment: Probit and Ordered-Probit regression results

Consider the results of the Probit estimation first: The coefficients of the trust variable are indeed significantly positive, that is higher levels of supplier trust are associated with less frequent quality issues. The size of the coefficients is definitely relevant from an economic perspective. Increasing trust by one standard deviation coincides with a decrease in the probability of quality problems by more than $8 \%$, if one disregards the identity of the customer. If one controls for the identity customer (OEM dummies) then there is an even stronger effect that corresponds to more than $13 \%$ difference. The difference between the two values is in itself interesting. One explanation is that the

\footnotetext{
${ }^{40} \mathrm{We}$ analogously observe assessments of the frequency of product related recalls. Performing the same exercise for these yields qualitatively identical results.
} 
OEM undertakes a complementary investment, in its absence both the supplier's trust and the quality of parts may decrease. In other words, the effect of trust on quality (via the suppliers' investment) is underestimated. In the ordered-Probit regressions, we find the same qualitative picture. Here, in the absence of customer fixed effects trust is not significantly correlated with investment, while controlling for customer fixed effects we obtain a strong and significant relationship with the expected sign. It is less surprising that composite/large parts are $20 \%$ more likely to generate quality/investment problems.

Overall, we conclude that the evidence from the results supports our first hypothesis: As far as investment can be measured by the (inverse) frequency of quality problems, higher levels of trust are associated with higher levels of investment by the supplier.

\subsection{Trust and Competition}

Our second central hypothesis is that higher levels of trust should be associated with more competition induced by the OEM. The supplier faces attempts at rent extraction by the OEM either through the exploitation of the hold-up situation, or through competition at the investment stage. More competition may then be associated with higher levels of compliance to property rights by the party with the superior bargaining power, and therefore higher levels of trust.

In view of the structure of our data, our model predicts a specific pattern: A positive association of trust and competition in the development phase, in which the supplier undertakes the relationship specific investment. The forces that drive this positive relationship are not in place in the pre-development (this phase is supplier specific but not model specific), or in series production (in this phase the tools used by the supplier are typically owned by the OEM). In line with our model, therefore, we would expect as an additional test of the theory a significantly weaker relationship in these phases. Notice that the extant literature on relational contracts literature would predict a negative relationship between competition and trust.

Our empirical test is therefore to analyze how supplier competition in the different stages of production - measured by the number of parallel suppliers involved in the pre-development, development and production of the specific model, respectively - are associated with our trust measure. In the basic specifications we use OLS as we are mainly interested in the correlations between the variables. Taking the structure of our 
data into account, since significant shares of the observations are at the lower limit of 1 supplier we also perform Tobit regressions. In the following specification $y_{i j}$ is the number of suppliers employed by customer (OEM) $j$ for part $i, \kappa$ a constant, $x$ is the trust measure and $Z$ the vector of control variables discussed before.

$$
y_{i j}=\kappa+\beta * x_{i j}+\gamma * Z_{i}+\epsilon_{i j}
$$

According to our second hypothesis we would expect a positive sign for $\beta$ in the specification for development. Higher levels of trust should be associated with a higher incentive to extract rents by means of more competition, that is employing more parallel suppliers.

\begin{tabular}{|c|c|c|c|}
\hline Variables & "Pre-development" & Development & "Series Production ${ }^{\natural}$ \\
\hline \multirow[t]{2}{*}{ trust index } & -.096 & $.171^{* *}$ & .055 \\
\hline & $(.325)$ & $(.037)$ & $(.141)$ \\
\hline \multirow[t]{2}{*}{ tech. soph. } & .083 & $-.408 * *$ & $-.317 * * *$ \\
\hline & $(.660)$ & $(.016)$ & $(.000)$ \\
\hline \multirow[t]{2}{*}{ size of part } & -.065 & $-.362^{*}$ & $-.401 * * *$ \\
\hline & $(.872)$ & $(.077)$ & $(.000)$ \\
\hline \multirow[t]{2}{*}{ interaction } & .243 & .089 & $.358 * * *$ \\
\hline & $(.585)$ & $(.757)$ & $(.000)$ \\
\hline \multirow[t]{2}{*}{ supplier revenues } & .002 & .009 & -.000 \\
\hline & $(.695)$ & $(.117)$ & $(.868)$ \\
\hline \multirow[t]{2}{*}{ constant } & 1.757 & 1.880 & 1.393 \\
\hline & $(.000)$ & $(.000)$ & $(.000)$ \\
\hline OEM-FE & yes & yes & yes \\
\hline \# obs. & 100 & 139 & 174 \\
\hline Adj. $R^{2}$ & .040 & .107 & .138 \\
\hline
\end{tabular}

Table 4: Trust and Competition: OLS-regression results

The results of the OLS (Table 4) and the Tobit (Table 5) regressions are qualitatively identical. Most importantly, the trust measure is positively and strongly (at the 5\% level) significant for the development stage only. The coefficient for pre-development is negative and not significant ( $\mathrm{p}$-value of around .3 for both specifications), the coefficient for the series-production phase is positive, but also not significantly so ( $p$-values of .14 and .22 , respectively). This not withstanding, its size is substantially smaller than the 


\begin{tabular}{|c|c|c|c|}
\hline Variables & Pre-development" & Development & Series Production ${ }^{\star}$ \\
\hline \multirow[t]{2}{*}{ trust index } & -.107 & $.337^{* *}$ & .227 \\
\hline & $(.291)$ & $(.050)$ & $(.220)$ \\
\hline \multirow[t]{2}{*}{ tech. soph. } & .081 & $-.969 * * *$ & $-1.386^{* * *}$ \\
\hline & $(.682)$ & $(.005)$ & $(.001)$ \\
\hline \multirow[t]{2}{*}{ size of part } & -.101 & $-1.072 * *$ & $-2.194^{* * *}$ \\
\hline & $(.811)$ & $(.014)$ & $(.001)$ \\
\hline \multirow[t]{2}{*}{ interaction } & .324 & .012 & $1.586^{*}$ \\
\hline & $(.487)$ & $(.958)$ & $(.072)$ \\
\hline \multirow[t]{2}{*}{ supplier revenues } & .002 & $.022^{*}$ & -.008 \\
\hline & $(.734)$ & $(.061)$ & $(.610)$ \\
\hline \multirow[t]{2}{*}{ constant } & 1.685 & 1.835 & .621 \\
\hline & $(.000)$ & $(.000)$ & $(.323)$ \\
\hline OEM-FE & yes & yes & yes \\
\hline \# obs. & 100 & 139 & 174 \\
\hline \# cens. obs & 13 & 80 & 144 \\
\hline Pseudo $R^{2}$ & .076 & .137 & .213 \\
\hline
\end{tabular}

Table 5: Trust and Competition: Tobit-regression results (lower bound $=1$ )

one of the development phase. The coefficient of trust for the development phase, .171, can readily be interpreted relative to the average number of suppliers employed during this stage, which is 1.51. Therefore, raising the trust measure by one standard deviation is associated with an increase of the number of suppliers competing of more than $10 \%$ of the average level. We take this to be strong support for our second hypothesis.

Considering the results in the other stages sheds further light on the issue and corroborates our characterization of the different phases. Noticeably, for the pre-development phase, none of the controls, including the size and sophistication of the part play a significant role. This reflects the observation that the non-model-specific fundamental research involved at this stage follows a different set of rules. It is often initiated purely by the upstream suppliers, and when it is not, the greater uncertainty involved in the project gives an additional incentive to involve more firms. On the other hand, the pattern of the other coefficients for series-production is very similar to the development stage. Further down the line in the product development life-cycle, as it becomes progressively easier to specify contractual details and product characteristics, the procurement phases are more easily comparable. One distinguishing feature between the development phase and series production though remains. Once the blueprints exist, the need for relation- 
ship specific investment by the supplier is substantially reduced. This is reflected in the difference in the importance of trust for the production procurement decisions and provides further support for our second hypothesis.

\section{Concluding Remarks}

Trust is an important ingredient in almost all meaningful social and economic interactions. While, largely due to availability of data, most empirical research on trust has focused on the willingness of individuals to trust others in general. We are here able to shed light on the role of trust as fostered or squandered in pairwise economic relationships. We first propose and model an intuitive definition for trust: In a bilateral relationship involving a hold-up situation, we define trust the belief by the party with the weaker bargaining power, that its counterpart will not exploit its stronger bargaining position by appropriating the whole surplus from the relationship.

We are then able to document how an OEM's investment in supplier trust, characterized by the OEM decision to forgo (often short-term) opportunities of appropriating rent, can pay off. Contractual relationships characterized by higher levels of trust are associated with significantly higher investment by suppliers, resulting in fewer failures and callbacks on the parts supplied.

More surprisingly, we also show that higher levels of trust by suppliers are associated with the downstream procurer's decision to have a larger number of upstream suppliers compete for the development, or production contract. In other words, more intense upstream competition is a substitute for the buyer's decision to exploit an existing hold-up situation. Indeed, the OEM that does not extract surplus using its superior bargaining power can appropriate a larger share of the surplus by increasing competition among suppliers and in this way enhancing its (endogenously determined) outside option without affecting the suppliers' incentives to invest. 


\section{Appendix: Descriptive Statistics}

\begin{tabular}{|l||c|c|c|c|}
\hline Variable & Mean (Std. Dev.) & Min & Max & Obs. \\
\hline When is supplier asked to participate? & $2.77(1.37)$ & 1 & 6 & 144 \\
\hline How often is progress coordinated? & $2.98(.57)$ & 1 & 5 & 151 \\
\hline Share of efforts absorbed by supplier & $3.50(1.33)$ & 1 & 5 & 142 \\
\hline Cost reimbursement if subsequent contract & $2.31(1.52)$ & 1 & 5 & 246 \\
\hline Cost reimbursement if no subsequent contract & $2.39(1.59)$ & 1 & 5 & 232 \\
\hline Specificity development objectives wrt... & $2.33(.97)$ & 1 & 5 & 350 \\
\hline .. content & $1.85(.96)$ & 1 & 5 & 350 \\
\hline .. time-frame & $2.22(1.14)$ & 1 & 5 & 343 \\
\hline .. financial engagement & \multicolumn{5}{|l|}{} \\
\hline OEM's supplier choice criteria: & $5.10(1.16)$ & 1 & 6 & 158 \\
\hline ... importance of supplier price & $4.70(.99)$ & 1 & 6 & 160 \\
\hline ... importance of duration cooperation & $4.89(.98)$ & 1 & 6 & 159 \\
\hline ... importance of trust & & \multicolumn{5}{|l}{} \\
\hline
\end{tabular}

Table 6: Relationship Characteristics: Pre-Development (Suppliers' view)

\begin{tabular}{|l||c|c|c|c|}
\hline Variable & Mean (Std. Dev.) & Min & Max & Obs. \\
\hline How specific and detailed are specifications? & $2.39(1.02)$ & 1 & 5 & 231 \\
\hline Supplier's degree of freedom & $2.91(.86)$ & 1 & 5 & 231 \\
\hline Desired degree of freedom & $3.62(.77)$ & 1 & 5 & 229 \\
\hline OEM's contribution to development & $2.37(1.10)$ & 1 & 5 & 200 \\
\hline Frequency of IPR conflicts & $2.24(.87)$ & 1 & 5 & 194 \\
\hline OEM's supplier choice criteria: & $5.37(.72)$ & 2.5 & 6 & 387 \\
\hline ... importance of supplier price & $4.52(1.00)$ & 1 & 6 & 387 \\
\hline ... importance of duration cooperation & $4.52(.98)$ & 1 & 6 & 387 \\
\hline ... importance of personal contact & $4.39(1.14)$ & 1 & 6 & 377 \\
\hline ... importance of certification & $4.90(.93)$ & 1 & 6 & 384 \\
\hline ... importance of trust
\end{tabular}

Table 7: Relationship Characteristics: Development (Suppliers' view) 


\begin{tabular}{|l||c|c|c|c|}
\hline Variable & Mean (Std. Dev.) & Min & Max & Obs. \\
\hline How often does OEM produce part himself? & $1.69(1.31)$ & 1 & 6 & 210 \\
\hline OEM's supplier choice criteria: & $5.70(.52)$ & 3 & 6 & 253 \\
\hline$\ldots$ importance of supplier price & $4.38(1.07)$ & 1 & 6 & 253 \\
\hline$\ldots$ importance of duration cooperation & $4.44(1.10)$ & 1 & 6 & 253 \\
\hline$\ldots$ importance of personal contact & $4.28(1.19)$ & 1 & 6 & 250 \\
\hline$\ldots$ importance of certification & $4.73(.98)$ & 1 & 6 & 252 \\
\hline$\ldots$ importance of trust &
\end{tabular}

Table 8: Relationship Characteristics: Series Production (Suppliers' view)

\begin{tabular}{|l||c|c|c|c|}
\hline Variable & Mean (Std. Dev.) & Min & Max & Obs. \\
\hline Number of competing suppliers & $2.16(.84)$ & 1 & 5 & 137 \\
\hline Frequency of subsequent development projects & $3.23(1.11)$ & 1 & 5 & 322 \\
\hline How often were projects discontinued in last 5 yrs. & $2.00(.88)$ & 1 & 5 & 139 \\
\hline How often were the following employed... & $4.43(1.26)$ & 1 & 6 & 351 \\
\hline .. preselection of a specific supplier & $3.95(1.44)$ & 1 & 6 & 338 \\
\hline ... procurement among a ltd. number of suppliers & \multicolumn{4}{|l|}{} \\
\hline
\end{tabular}

Table 9: Procurement Decisions: Pre-Development (Suppliers' view)

\begin{tabular}{|l||c|c|c|c|}
\hline Variable & Mean (Std. Dev.) & Min & Max & Obs. \\
\hline Frequency joint procurement dev. and production & $3.76(1.24)$ & 1 & 5 & 363 \\
\hline Number of suppliers employed during... & \multicolumn{4}{|l|}{} \\
\hline .. product planning & $2.22(1.13)$ & 1 & 5 & 167 \\
\hline$\ldots$ product specification & $2.03(1.02)$ & 1 & 5 & 177 \\
\hline$\ldots$ concept development & $2.12(1.07)$ & 1 & 5 & 208 \\
\hline$\ldots$ detailed development & $1.51(0.90)$ & 1 & 5 & 210 \\
\hline How often were the following employed... & \multicolumn{5}{|l|}{} \\
\hline$\ldots$ preselection of a specific supplier & $3.06(1.52)$ & 1 & 6 & 259 \\
\hline$\ldots$ procurement among a ltd. number of suppliers & $5.18(1.10)$ & 1 & 6 & 264 \\
\hline$\ldots$ open procurement & $1.97(1.41)$ & 1 & 6 & 255 \\
\hline
\end{tabular}

Table 10: Procurement Decisions: Development (Suppliers' view) 


\begin{tabular}{|l||c|c|c|c|}
\hline Variable & Mean (Std. Dev.) & Min & Max & Obs. \\
\hline Number of suppliers employed... & $1.20(.58)$ & 1 & 5 & 251 \\
\hline$\ldots$ at production start & $1.47(.78)$ & 1 & 5 & 249 \\
\hline$\ldots$ after 1-2 years & $1.59(.81)$ & 1 & 5 & 246 \\
\hline$\ldots$ after more than 2 years & \multicolumn{5}{|l}{} \\
\hline How often were the following employed... & $2.98(1.63)$ & 1 & 6 & 248 \\
\hline$\ldots$ preselection of a specific supplier & $4.55(1.52)$ & 1 & 6 & 248 \\
\hline$\ldots$ procurement among a ltd. number of suppliers & $2.44(1.66)$ & 1 & 6 & 243 \\
\hline$\ldots$ open procurement &
\end{tabular}

Table 11: Procurement Decisions: Series Production (Suppliers' view) 


\section{References}

Aghion, P., Y. Algan, P. Cahuc, And A. Shleifer (2008): "Regulation and Distrust," Harvard University, mimeo.

Aghion, P., M. Dewatripont, and P. Rey (2002): "On partial contracting," European Economic Review, 46, 745-753.

Akerlof, G. A., And J. L. Yellen (1990): "The Fair Wage-Effort Hypothesis and Unemployment," The Quartely Journal of Economics, 105, 255-283.

Baker, G., R. Gibbons, and K. J. Murphy (1994): "Subjective Performance Measures in Optimal Incentive Contracts," The Quarterly Journal od Economics, 109(4), $1125-1156$.

Ben-Shahar, O., and J. J. White (2006): "Boilerplate and Economic Power in Auto Manufacturing Contracts," Michigan Law Review, 104, 953-82.

Bergemann, D., And J. VÄLimÄKI (1996): "Learning and Strategic Pricing," Econometrica, 64, 1125-49.

Bottazzi, L., M. Da Rin, and T. Hellmann (2007): "The Importance of Trust for Investment: Evidence from Venture Capital," mimeo.

(2009): "What is the role of legal systems in financial intermediation? Theory and evidence," Journal of Financial Intermediation, 18, 559-598.

Brown, M., A. Falk, and E. Fehr (2004): "Relational Contracts and the Nature of Market Interactions," Econometrica, 72(3), 747-780.

Bull, C. (1987): "The Existence of Self-Enforcing Implicit Contracts," The Quartely Journal of Economics, 102, 147-159.

Butler, J., P. Giuliano, and L. Guiso (2009): "The Right Amount of Trust," NBER Working Paper No. 15344.

Calzolari, G., and G. Spagnolo (2009): "Relational Contracts and Competitive Screening," CEPR Discussion Paper No. 7434. 
FeHr, E. (2009): "On the Economics and Biology of Trust," Journal of the European Economic Association, 7, 235-266.

Felli, L., ANd C. Harris (1996): "Learning, Wage Dynamics, and Firm-Specific Human Capital," Journal of Political Economy, 104, 838-68.

GibBons, R. (2011): Organizational Economics. Princeton University Press, Princeton, NJ, forthcoming.

Guiso, L., P. Sapienza, and L. Zingales (2004): "The Role of Social Capital in Financial Development," American Economic Review, 94, 526-556.

(2005): “Trusting the Stock Market," NBER Working Paper 11648.

(2006): "Does Culture Affect Economic Outcomes?," Journal of Economic Perspectives, 20, 23-48.

(2009): "Cultural Biases in Economic Exchange?," The Quarterly Journal of Economics, 124, 1095-1131.

La Porta, R., F. Lopez-de-Silanes, A. Shleifer, and R. W. Vishny (1997): "Trust in Large Organizations," American Economic Review, 87(2), 333-338.

Levin, J. (2003): "Relational Incentive Contracts," American Economic Review, 93(3), $835-857$.

MacLeod, W. B. (2007): "Reputations, Relationships and Contract Enforcement," Journal of Economic Literature, 45, 595-628.

Müller, F., K. O. Stahl, and F. Wachtler (2008): "Upstream Relationships in the Automotive Industry: A Contractual Perspective," mimeo.

Sapienza, P., A. Toldra, and L. Zingales (2007): "Understanding Trust," NBER WP $1338 \%$.

Taylor, C. R., and S. N. Wiggins (1997): "Competition or Compensation: Supplier Incentives Under the American and Japanese Subcontracting Systems," The American Economic Review, 87, 598-618. 